\title{
Effect of intravenous lidocaine on propofol consumption in elderly patients undergoing colonoscopy: a double-blinded, randomized, controlled trial
}

Meizhen Li, Weiqi Ke and Shaohui Zhuang ${ }^{*}$

\begin{abstract}
Background: Elderly patients undergoing colonoscopy with propofol as sedation are prone to respiratory or cardiovascular complications. Intravenous lidocaine has analgesic efficacy and reduces propofol consumption during surgery. Here, the effect of intravenous lidocaine on propofol consumption was evaluated in elderly patients undergoing colonoscopy.

Methods: Patients were randomly allocated to receive intravenous lidocaine $(1.5 \mathrm{mg} / \mathrm{kg}$ bolus dose, followed by a $2 \mathrm{mg} / \mathrm{kg} / \mathrm{h}$ continuous infusion during the procedure; Group L) or a placebo (saline; Group N). During the procedure, sedation was achieved by propofol. The following outcomes were recorded: total propofol consumption; time to loss of consciousness; number of airway modifications; time to the first airway intervention; incidence of sedation-related events; pain score after awakening; endoscopists' and patients' satisfaction scores; memory level of the procedure; and adverse events within $24 \mathrm{~h}$ postoperatively.

Results: Compared with Group N, propofol consumption was reduced by 13.2\% in Group L $(100.30 \pm 25.29$ mg vs. $115.58 \pm 27.52 \mathrm{mg}$, respectively, $p=0.008$ ). Kaplan-Meier curves showed that the median time to the loss of consciousness episode was shorter in Group L than in Group N (40 s vs. 55 s, respectively, log rank $p<0.0001$ ). The number of airway modifications, time to the first airway intervention, incidence of sedation-related events, time to awakening, pain score after awakening, endoscopists' and patients' satisfaction scores, memory level of the procedure and adverse events within $24 \mathrm{~h}$ postoperatively did not differ between the two groups ( $p>0.05)$.
\end{abstract}

Conclusions: Intravenous lidocaine can reduce propofol consumption in elderly patients undergoing colonoscopy, with quicker time to loss of consciousness.

Trial registration: The clinical trial was registered at (12/01/2021, ChiCTR2100042001).

Keywords: Intravenous lidocaine, Elderly patients, Propofol, Colonoscopy

*Correspondence: doctorzsh@163.com

Department of Anesthesiology, the First Affiliated Hospital of Shantou University Medical College, No. 57 Changping Road, Jinping District,

Shantou, Guangdong Province, China

\begin{abstract}
Background
Colonoscopy is used for Colorectal cancer (CRC) screening in elderly patients in an increasing number of countries [1]. Propofol has become the first choose sedative drug for colonoscopy [2] because of its rapid action, strong sedation, short half-life, rapid recovery, and higher satisfaction [3]. However, it was reported that respiratory
\end{abstract} original author(s) and the source, provide a link to the Creative Commons licence, and indicate if changes were made. The images or other third party material in this article are included in the article's Creative Commons licence, unless indicated otherwise in a credit line to the material. If material is not included in the article's Creative Commons licence and your intended use is not permitted by statutory regulation or exceeds the permitted use, you will need to obtain permission directly from the copyright holder. To view a copy of this licence, visit http://creativecommons.org/licenses/by/4.0/. The Creative Commons Public Domain Dedication waiver (http://creativeco mmons.org/publicdomain/zero/1.0/) applies to the data made available in this article, unless otherwise stated in a credit line to the data. 
depression and cardiovascular events were common sedation-related complications during propofol-based sedation [4, 5], especially in elderly patients [6]. Moreover, age-related pharmacokinetic changes and patient comorbidities are of great concern during the sedation process. Midazolam and opioid drugs combined with propofol can reduce the consumption of propofol, and both can result in respiratory depression $[7,8]$. Therefore, it is of crucial clinical value for anaesthesiologists to find the optimal adjunct drug to reduce propofol consumption and focus on the tolerability of propofol use in elderly patient undergoing colonoscopy.

In recent years, intravenous lidocaine as a propofoladjuvant drug has been widely used in anaesthesia for reducing pain, decreasing opioid or sedative consumption, and accelerating postoperative bowel function recovery in many surgical procedures [9-11]. Intravenous lidocaine can reduce the requirement of propofol by $50 \%$, with less postoperative pain and fatigue in colonoscopy patients [12]. However, there are no double-blinded, randomized, controlled trials focusing on the use of intravenous lidocaine $(1.5 \mathrm{mg} / \mathrm{kg}$, followed by $2 \mathrm{mg} / \mathrm{kg} / \mathrm{h})$ in elderly patients undergoing colonoscopy. Therefore, the study aimed to investigate the effect of intravenous lidocaine on propofol consumption in elderly patients undergoing colonoscopy.

\section{Methods}

\section{Ethical approval of the study protocol}

After approval by the Ethics Committee of the First Affiliated Hospital of Shantou University Medical College (No. B-2021-005) and registration on www.chictr. org.cn (12/01/2021, ChiCTR2100042001), this study was performed in the Endoscopic Unit of the First Affiliated Hospital of Shantou University Medical College in Guangdong, China, from January 13, 2021, to May 31, 2021. All the patients who participated in this study voluntarily signed written informed consent forms. This study complied with the Declaration of Helsinki and adhered to the applicable CONSORT guidelines.

\section{Participants}

Patients older than 65 years of age with American Society of Anaesthesiologists (ASA) grading scores of I to III and a body mass index (BMI) from 18 to $30 \mathrm{~kg} / \mathrm{m}^{2}$ scheduled for colonoscopy were enrolled. The exclusion criteria were as follows: 1) patients with a history of allergies to drugs related to the study; 2) patients with severe heart, lung, liver and kidney diseases; 3 ) patients with central nervous system diseases or mental disorders; 4) patients with hyperalgesia or refractory cancer pain; and 5) patients who refused to sign the informed consent form.
In addition, during the operation, early procedure termination due to poor intestinal cleansing may have led to less propofol consumption. Patients with an operation time over $40 \mathrm{~min}$ were also excluded because patients whose procedure time was more than $40 \mathrm{~min}$ were awoken by the endoscopists in the Endoscopic Unit. Endoscopists hope to complete the procedure by changing a patient's body position. For example, the left lateral decubitus position is commonly changed to the prone position so that the colonoscope may better pass the splenic flexure or the hepatic flexure of the colon. In this case, an anaesthesiologist usually stands by and administrates propofol if necessary. These means that our protocol breaks off at this time, and the total propofol consumption would be different compared to the propofol dose in the study.

\section{Sample size estimation}

Estimation of the sample size was undertaken by PASS 15.0 (NCSS, Kaysville, UT, USA). The primary outcome of this study was the total propofol consumption. Based on the results of our previous study involving 20 patients, the total consumption of propofol for colonoscopy was $124 \pm 36 \mathrm{mg}$ in Group N and $106 \pm 19 \mathrm{mg}$ in Group L. With a significance level of 0.05 (two-sided) and power of $80 \%, 42$ patients were required in each group. Assuming a loss of follow-up of $8 \%, 46$ patients were required per group, and a total of 92 patients was finally included.

\section{Randomization and blinding}

Ninety-two patients were randomly allocated to the 2 groups. Randomization was determined with block sizes of 4 and an allocation ratio of 1:1. Eligible participants were assigned to receive either intravenous lidocaine (Group L) or normal saline (Group N) according to a computer-generated randomization schedule. This randomization sequence was retained in an opaque envelope. The drugs were prepared by a nurse and administered by an anaesthesiologist who also recorded data. The syringes containing lidocaine or saline were identical because the solutions were clear and colourless. Other individuals cannot identify the solution through its appearance, colour or smell. The patients, endoscopists and anaesthesiologists were blinded to the group allocation.

\section{Study design}

After receiving vascular access in the right upper limb, the patients were placed in the left lateral decubitus position with a nasal cannula oxygen supply of $2 \mathrm{~L} / \mathrm{min}$ ute. The electrocardiogram, peripheral oxygen saturation index $\left(\mathrm{SpO}_{2}\right)$, and noninvasive blood pressure were monitored. All measurements were recorded at intervals of $3 \mathrm{~min}$. 
A bolus dose of $1 \%$ lidocaine $(1.5 \mathrm{mg} / \mathrm{kg})$ was intravenously administered within 2 min before anesthesia induction, followed by a continuous infusion of $2 \mathrm{mg} /$ $\mathrm{kg} / \mathrm{h}$ (Group L), or the same volume of normal saline was administered (Group N). An initial bolus of propofol $(1 \mathrm{mg} / \mathrm{kg})$ was given to all patients. A repeated dose of $0.5 \mathrm{mg} / \mathrm{kg}$ of propofol was titrated if necessary to acquire a state of unconsciousness. A dose of sufentanil $(0.1 \mu \mathrm{g} / \mathrm{kg})$ was administered after loss of consciousness. The colonoscope was inserted by an endoscopist after sufentanil was administered. A repeated dose of $0.5 \mathrm{mg} / \mathrm{kg}$ of propofol was given if patients expressed discomfort (grimaces, involuntary movements). Propofol was intravenously administered intermittently instead of continuously infused. When subclinical respiratory depression $\left(90 \% \leq \mathrm{SpO}_{2}<95 \%\right)$ occurred, the jaw-thrust manoeuvre was performed to open the airway. When hypoxia $\left(75 \% \leq \mathrm{SpO}_{2}<90 \%\right.$ for less than $\left.60 \mathrm{~s}\right)$ occurred, in addition to the jaw-thrust manoeuvre, the oxygen flow rate was increased from 2 to $6 \mathrm{~L} /$ minute. Mask ventilation was performed when severe hypoxia $\left(\mathrm{SpO}_{2}<75 \%\right.$ or $75 \% \leq \mathrm{SpO}_{2}<90 \%$ for $60 \mathrm{~s}$ ) occurred [13]. Tracheal intubation was necessary if severe hypoxia could not be corrected through mask ventilation, which was decided by the anaesthesiologist. If hypotension (a mean arterial pressure (MAP) $<65 \mathrm{mmHg}$ or a systolic blood pressure (SBP) descending $20 \%$ basal value) was continuously measured twice, ephedrine $(5 \mathrm{mg})$ was administered. If bradycardia (heart rate (HR) $<50 \mathrm{bpm}$ ) occurred, atropine $(0.5 \mathrm{mg})$ was administered.

The infusion of lidocaine was immediately stopped at the end of the procedure. The procedure time (defined as the time from colonoscope insertion into the anus to withdrawal) was recorded. The satisfaction score for sedation was obtained from the endoscopists. The pain score and memory level were evaluated for patients after awakening. Adverse events within $24 \mathrm{~h}$ postoperatively and the patients' satisfaction scores for the procedure were assessed by telephone for ambulatory patients or interview for inpatients.

\section{Study outcomes}

The primary outcome was the total propofol consumption. The secondary outcomes were as follows: the time to loss of consciousness (defined as the time from intravenous propofol to the loss of the eyelash reflex); the number of airway modifications [5] (defined as opening the airway using the jaw-thrust manoeuvre, increasing the oxygen flow rate or mask ventilation); the time to the first airway intervention; the incidence of sedationrelated events [5] (defined as an $\mathrm{SpO}_{2}<90 \%$, hypotension requiring vasopressors, or bradycardia $(\mathrm{HR}<50 \mathrm{bpm})$ ); the time to awakening (defined as the time from the final time of intravenous propofol to awakening); pain scores (VAS, visual analogue scale, from 0 to 10 ; the higher the score, the more intense the pain) after awakening; memory level of procedure $(0=$ no memory; $1=$ memory only at the end; $2=$ multiple memories); satisfaction scores (from 0 to 10; the higher the score, the more satisfied) of the endoscopists and patients; and adverse events (such as dizziness, nausea or vomiting) within $24 \mathrm{~h}$ postoperatively.

\section{Statistical analysis}

Data were analysed using SPSS 25.0 (SPSS Inc., Chicago, IL, USA) and Prism 9.0 (GraphPad Software, La Jolla, CA, USA). The distribution of variables was evaluated for normality using the Kolmogorov-Smirnov test. Parametric data are presented as the mean \pm standard deviation, while nonparametric data are presented as medians with interquartile ranges. Categorical variables are expressed as percentages and were analysed using the $\chi^{2}$ or Fisher's exact test. Continuous variables with a normal distribution were analysed using the two-sample $t$ test, whereas continuous variables with a nonnormal distribution were analysed with the Mann-Whitney U test. Kaplan-Meier survival curve analysis with the log-rank test was performed to evaluate the effect of intravenous lidocaine on the time to loss of consciousness. A value of $p<0.05$ was considered significant.

\section{Results}

Ninety-two patients were included and allocated to either Group L or Group N. One patient in each group were prematurely excluded due to poor intestinal cleansing. One patient in Group L and two patients in Group $\mathrm{N}$ underwent a colonoscopy for more than $40 \mathrm{~min}$. Finally, 44 patients in Group L and 43 patients in Group $\mathrm{N}$ were enrolled for analysis in this study (Fig. 1). The demographic characteristics and procedure details were not different between the two groups (Table 1). Compared with Group N, propofol consumption was reduced by $13.2 \%$ in Group L $(100.30 \pm 25.29 \mathrm{mg}$ vs. $115.58 \pm 27.52 \mathrm{mg}$, respectively, $p=0.008$ ). There was no significant difference in the induction dose of propofol between the two groups, while the supplemental dose was significantly smaller in Group L than in Group $\mathrm{N}(28.52 \pm 22.00 \mathrm{mg}$ vs. $41.35 \pm 24.23 \mathrm{mg}$, respectively, $p=0.014$ ) (Fig. 2). The Kaplan-Meier curve showed that the median time to consciousness loss was significantly shorter in Group L than in Group N (40s vs. 55 s, respectively, hazard ratio $=2.801,95 \%$ CI: $1.742-4.502$, $p<0.0001$ ) (Fig. 3). The number of airway modifications, time to the first airway modification, incidence of sedation-related events, pain scores after awakening, satisfaction scores of the endoscopists and patients, memory 


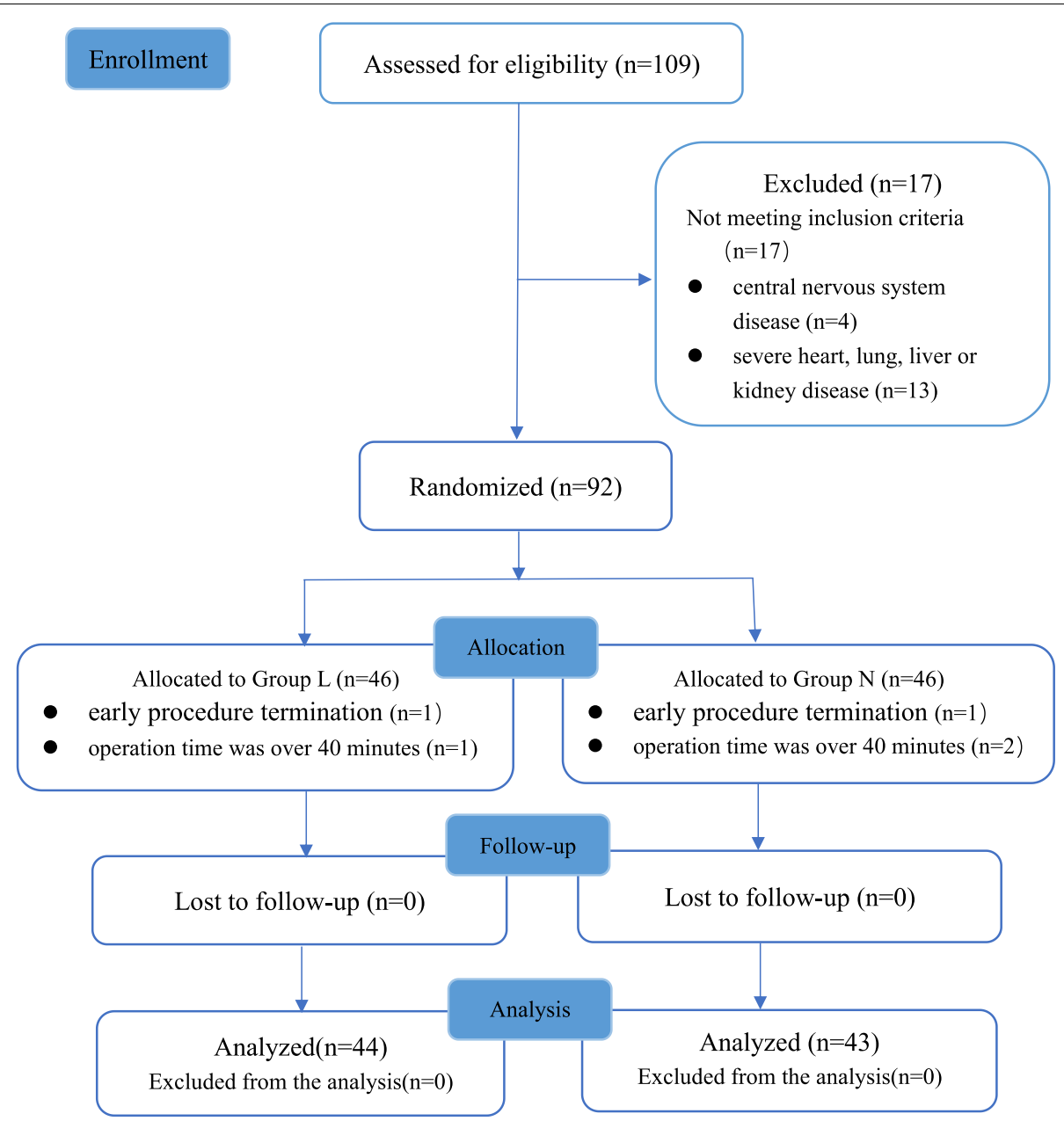

Fig. 1 Study population flow diagram

level of procedure and adverse events within $24 \mathrm{~h}$ postoperatively did not differ significantly between the two groups (Table 2).

\section{Discussion}

This study demonstrated three key findings. First, intravenous lidocaine can reduce propofol consumption in elderly patients undergoing colonoscopy. Second, the time for patient loss of consciousness was significantly decreased by intravenous lidocaine administration. Third, there was no evidence of significant lidocainerelated side effects in elderly patients with this dose of intravenous lidocaine administration.

In this study, intravenous lidocaine resulted in a $13.2 \%$ reduction in propofol requirements for colonoscopy. The propofol-sparing effect of lidocaine was not observed during the induction of the anesthesia process, whereas this sparing effect was only observed during surgical stimulation, which suggested that lidocaine mediated an antinociceptive action [14, 15]. The supplemental dose of propofol was significantly lower after intravenous lidocaine administration, which was consistent with the findings of Forster and his colleagues [12]. However, Forster et al. found that using intravenous lidocaine in colonoscopy reduced propofol consumption by $50 \%$, which was significantly higher than the reduction of propofol in this study. Moreover, the procedure time in Forster's study was obviously longer ( 25.7 vs. $12.2 \mathrm{~min}$ ). It was reported that the dose of the sedative was impacted by a variety of factors, including the procedure type and time and the patient's age, ASA status, and comorbidities [16]. In this study, these factors did not differ significantly between the two groups. Thus, the procedure time in this trial might be the main factor impacting the dose of the sedative used in this trial. The procedure time in this study might have been too short to observe the propofol-sparing effect of intravenous lidocaine. This may partly explain why a 
Table 1 The demographic characteristics and procedure details

\begin{tabular}{lll}
\hline & Group L $(\boldsymbol{n}=\mathbf{4 4})$ & Group N $(\boldsymbol{n}=\mathbf{4 3})$ \\
\hline Age, $\mathrm{y}$ & $69.00(66.00-71.75)$ & $69.00(66.00-73.00)$ \\
Sex, Male & 28 & 27 \\
Height, cm & $163.43 \pm 7.64$ & $162.51 \pm 6.76$ \\
Weight, $\mathrm{kg}$ & $59.77 \pm 8.69$ & $58.06 \pm 8.53$ \\
BMI, kg/m & $22.38 \pm 2.91$ & $21.95 \pm 2.64$ \\
ASA scores I/II/II & $13 / 30 / 1$ & $14 / 24 / 5$ \\
Coexisting disease & & \\
$\quad$ Hypertension & 13 & 8 \\
$\quad$ Diabetes mellitus & 13 & 8 \\
$\quad$ Coronary artery disease & 1 & 1 \\
Main procedure & & \\
$\quad$ Examination & 19 & 14 \\
Polypectomy & 18 & 24 \\
$\quad$ Biopsy & 7 & 5 \\
Procedure time, min & $15.11 \pm 7.93$ & $16.52 \pm 7.12$ \\
Ambulatory patient & 9 & 8 \\
1\% lidocaine, mg & $121.04 \pm 23.93$ & - \\
\hline
\end{tabular}

$B M I$ body mass index, ASA American Society of Anesthesiologists

$15 \mathrm{mg}$ reduction in propofol might not be meaningful in clinical situations, although it was statistically significant. Meanwhile, the satisfaction scores of the patients and endoscopists did not differ significantly between the two groups, which suggested that the propofolsparing effect of intravenous lidocaine was not at the expense of the endoscopists' working conditions.
Abdominal pain, a common complication of colonoscopy, is associated with swelling of the intestinal cavity caused by water and gas injections or mechanical stretching of the intestinal wall caused by the enteroscope during colonoscopy [17]. The analgesic mechanism of intravenous lidocaine is complex and still remains unclear. This finding might correlate with the wellknown voltage-gated open and inactivated sodium channel blockade effect $[18,19]$. In addition, lidocaine can directly stimulate opiate receptors while suppressing polysynaptic reflexes in the spinal dorsal horn $[20,21]$. The pain scores in this study did not differ after intravenous lidocaine, which was different from those in previous research by Forster [12] and Liu [22]. A possible explanation for this observation might be that the continuously infused dose of lidocaine was larger in the two previous studies. Meanwhile, the use of sufentanil also contributed to an analgesic effect. Additionally, the endoscopists extracted the gas from the bowel when the enteroscope was withdrawn from the ileocecum, which might relieve bowel distension. Therefore, the analgesic effect of intravenous lidocaine may be hidden.

Kaplan-Meier and log-rank test analyses showed that the median duration time of consciousness loss in Group L was decreased by approximately one-third, which was similar to that in the research by Liu [22] and Li [23]. Lidocaine combined with propofol shortened the duration of consciousness loss. However, lidocaine did not affect the effect-site concentrations of propofol required for consciousness loss, and the plasma concentration of

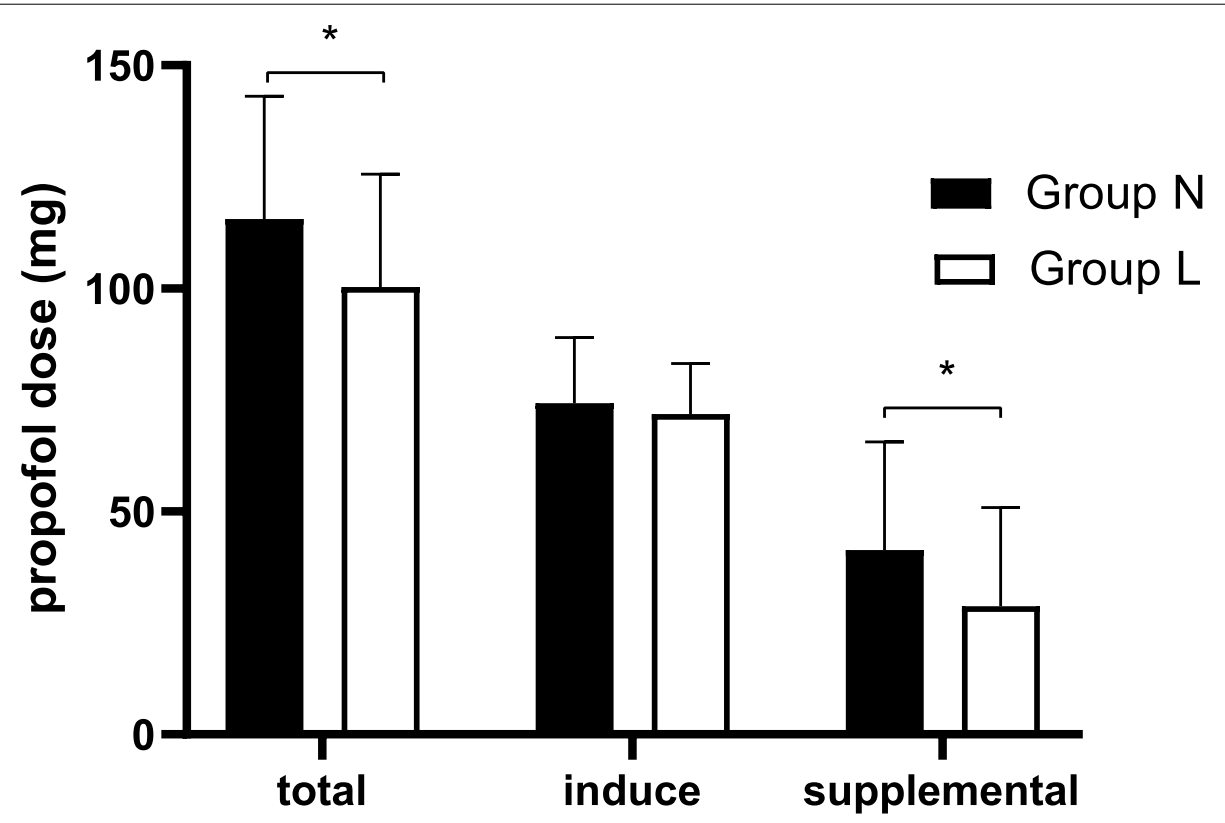

Fig. 2 The propofol doses used in the study. Data are the means (SDs). ${ }^{*} p<0.05$ 


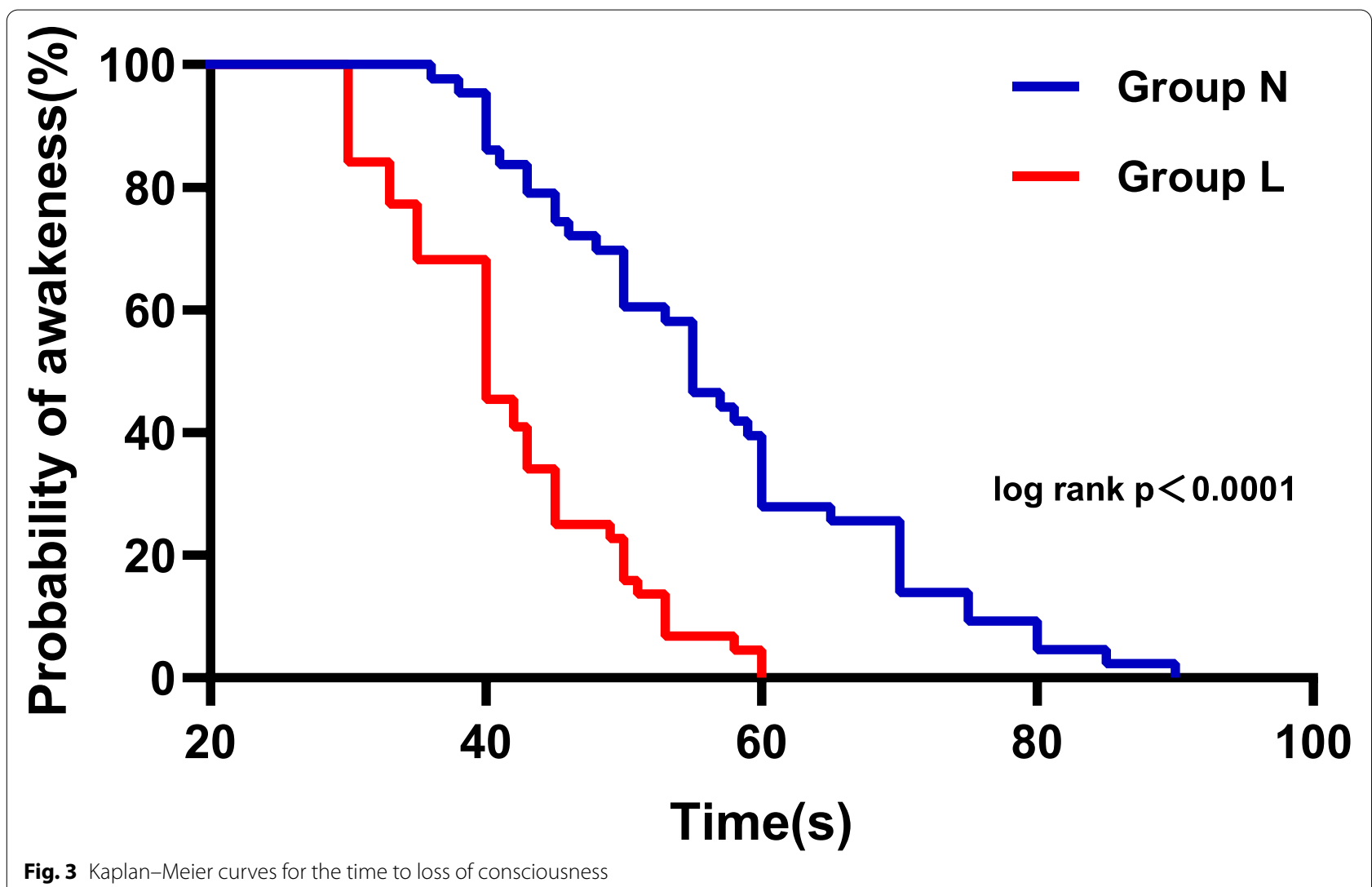

Table 2 Secondary outcomes of the study

\begin{tabular}{|c|c|c|c|}
\hline & Group L $(n=44)$ & Group N $(n=43)$ & $p$ \\
\hline Time to loss of consciousness, $\mathrm{s}$ & $40[35-48]$ & $55[45-70]$ & $<0.001$ \\
\hline Number of airway modifications, times & $1[0-2]$ & $0[0-2]$ & 0.645 \\
\hline Time to the first airway intervention, $\mathrm{s}$ & $76.50[55.7-163.75]$ & $61.50[30.00-78.75]$ & 0.137 \\
\hline Number of sedation-related events, times & 24 & 23 & 0.896 \\
\hline Time to awakening, min & $7.57 \pm 2.39$ & $7.79 \pm 2.45$ & 0.673 \\
\hline Pain scores, awake (VAS >0) & 4 & 8 & 0.198 \\
\hline Patients'satisfaction scores & $10.0[9.0-10.0]$ & $9.0[10.0-10.0]$ & 0.118 \\
\hline Endoscopists' satisfaction scores & $9.6[9.5-10.0]$ & $9.6[9.5-10.0]$ & 0.698 \\
\hline Memory level & & & 0.749 \\
\hline 0, no memory & 36 & 34 & \\
\hline 1 , memory only at the end & 6 & 8 & \\
\hline 2, multiple memories & 2 & 1 & \\
\hline \multicolumn{4}{|l|}{ Adverse events within $24 \mathrm{~h}$} \\
\hline Dizziness & 11 & 4 & 0.053 \\
\hline Nausea/vomiting & 1 & 0 & $>0.999$ \\
\hline
\end{tabular}

VAS visual analogue scale

propofol was not measured in this study. There seems to be a potential pharmacokinetic interaction between these two drugs, which needs to be clarified in future research.
Our results showed that the number of airway modifications and the incidence of sedation-related events did not differ significantly between the two groups. The potential clinical benefits of reducing the propofol dosage 
when combined with intravenous lidocaine were not ascertained. However, Li et al. [23] demonstrated that compared with propofol alone, lidocaine combined with propofol could significantly reduce the number of oxygen desaturation and apnea episodes in obese patients during colonoscopy, while the hemodynamic parameters during the procedure were similar between the two groups. Interestingly, another study from Chen et al. [24] clarified that lidocaine combined with propofol increased hemodynamic stability in elderly patients when compared with propofol alone, while the $\mathrm{SpO}_{2}$ index did not differ. It might be that we focused on elderly patients rather than obese patients, who have a higher incidence of hypoxemia. Although the study population of Chen et al. was the same as ours, the continuously infused dose of lidocaine was different. Whether elderly patients could benefit from reduction on propofol-induced adverse events by intravenous lidocaine still requires a larger sample size and multicenter trial to find the answer.

Doses of lidocaine that exceed safe limits might cause neurological or cardiovascular toxicity, which could be dangerous in elderly individuals. In our study, the safe dose of lidocaine was recommended in the 2016 Enhanced Recovery After Surgery guidelines for gastrointestinal surgery [25]. In addition, all the patients in Group L were observed closely during the perioperative period and for $24 \mathrm{~h}$ postoperatively, and none of them showed lidocaine-related side effects. The safety of the administration of lidocaine in our study was adequately guaranteed.

There are some limitations in this study. First, this study mostly included patients who were relatively healthy (ASA I III) and did not include high-risk patients (ASA IV) who were absolutely more vulnerable to propofol. Second, the evaluation of the sedation level and dose supplementation only depended on subjective observation techniques. With monitoring tools such as the BIS index or Narcotrend, the administration of propofol might have been more accurate. Third, the blood concentrations of lidocaine were not monitored. Fourth, compared with Group N, propofol consumption in Group L was reduced by $13.2 \%(100.30 \pm 25.29 \mathrm{mg}$ vs. $115.58 \pm 27.52 \mathrm{mg}$, respectively). Assuming an alpha error of 0.05 (two-sided) and a power of 0.8 , the sample size was calculated to be 48 patients per group. However, the actual power was approximately $75 \%$ in our study, with a total of 87 patients. Thus, this study was underpowered compared to a power of 0.8 that was estimated when we designed this study. Last, the time to awakening did not differ between the two groups, for which we defined the awakening time as that from the final time administering intravenous propofol to awakening. Propofol was intravenously administered intermittently, and continuous infusion made it easier to determine a different awakening time.

\section{Conclusion}

Intravenous lidocaine can reduce propofol consumption in elderly patients undergoing colonoscopy, with quicker time to loss of consciousness. The safety of the administration of lidocaine in our study was adequately guaranteed. However, the potential clinical benefits of the reduction in propofol-induced adverse events were not ascertained.

\section{Abbreviations}

CRC: Colorectal cancer; ASA: American Society of Anaesthesiologists; BMI: Body mass index; $\mathrm{SpO}_{2}$ : Peripheral oxygen saturation index; MAP: Mean arterial pressure; SBP: Systolic blood pressure; HR: Heart rate; VAS: Visual analogue scale.

\section{Acknowledgements}

The authors would like to express their gratitude to Professors Yu Zhang and Shuxian Chen and the Endoscopic Unit of the First Affiliated Hospital of Shantou University Medical College.

\section{Authors' contributions}

Li and Ke contributed equally to this work. (I) Conception and design: All authors; (II) Data collection and analysis: MZL; (III) Manuscript writing: WQK and MZL; (IV) Final approval of the manuscript: All authors.

Funding

No funding was received for this article.

\section{Availability of data and materials}

The datasets generated during and analyzed during the current study are not publicly available due to institutional restrictions but are available from the corresponding author on reasonable request.

\section{Declarations}

\section{Ethics approval and consent to participate}

The study was approved by the Ethics Committee of the First Affiliated Hospital of Shantou University Medical College (No. B-2021-005) on the basis of the Declaration of Helsinki. Chairman of the ethics committee: MuYao Jiang Email: sdfyllwyh@163.com. Written informed consent forms were signed by the patients or their guardians.

\section{Consent for publication}

Not applicable. The study did not contain any individual person's data in any form (including individual details, images or videos).

\section{Competing interests}

The authors declare that they have no competing interests.

Received: 29 August 2021 Accepted: 28 February 2022

Published online: 04 March 2022

References

1. Schreuders EH, Ruco A, Rabeneck L, Schoen RE, Sung JJ, Young GP, et al. Colorectal cancer screening: a global overview of existing programmes. Gut. 2015;64(10):1637-49.

2. Zhou S, Zhu Z, Dai W, Qi S, Tian W, Zhang Y, et al. National survey on sedation for gastrointestinal endoscopy in 2758 Chinese hospitals. Br J Anaesth. 2021;127(1):56-64. 
3. Eberl S, Preckel B, Bergman JJ, van Dieren S, Hollmann MW. Satisfaction and safety using dexmedetomidine or propofol sedation during endoscopic oesophageal procedures: a randomised controlled trial. Eur J Anaesthesiol. 2016;33(9):631-7.

4. Berzin TM, Sanaka S, Barnett SR, Sundar E, Sepe PS, Jakubowski M, et al. A prospective assessment of sedation-related adverse events and patient and endoscopist satisfaction in ERCP with anesthesiologistadministered sedation. Gastrointest Endosc. 2011;73(4):710-7.

5. Cote GA, Hovis RM, Ansstas MA, Waldbaum L, Azar RR, Early DS, et al. Incidence of sedation-related complications with propofol use during advanced endoscopic procedures. Clin Gastroenterol Hepatol. 2010;8(2):137-42.

6. Geng W, Jia D, Wang Y, Jin S, Ren Y, Liang D, et al. A prediction model for hypoxemia during routine sedation for gastrointestinal endoscopy. Clinics (Sao Paulo). 2018;73:e513.

7. Bailey PL, Pace NL, Ashburn MA, Moll JW, East KA, Stanley TH. Frequent hypoxemia and apnea after sedation with midazolam and fentanyl. Anesthesiology. 1990;73(5):826-30.

8. Welzing L, Oberthuer A, Junghaenel S, Harnischmacher U, Stutzer $H$, Roth B. Remifentanil/midazolam versus fentanyl/midazolam for analgesia and sedation of mechanically ventilated neonates and young infants: a randomized controlled trial. Intensive Care Med. 2012;38(6):1017-24.

9. Kim DH, Park JY, Yu J, Lee SA, Park S, Hwang JH, et al. Intravenous Lidocaine for the prevention of postoperative catheter-related bladder discomfort in male patients undergoing transurethral resection of bladder tumors: a randomized, double-blind, controlled trial. Anesth Analg. 2020;131(1):220-7.

10. Song $X$, Sun Y, Zhang X, Li T, Yang B. Effect of perioperative intravenous lidocaine infusion on postoperative recovery following laparoscopic cholecystectomy-a randomized controlled trial. Int J Surg. 2017;45:8-13.

11. Cooke C, Kennedy ED, Foo I, Nimmo S, Speake D, Paterson HM, et al. Meta-analysis of the effect of perioperative intravenous lidocaine on return of gastrointestinal function after colorectal surgery. Tech Coloproctol. 2019;23(1):15-24.

12. Forster C, Vanhaudenhuyse A, Gast P, Louis E, Hick G, Brichant JF, et al. Intravenous infusion of lidocaine significantly reduces propofol dose for colonoscopy: a randomised placebo-controlled study. Br J Anaesth. 2018;121(5):1059-64.

13. Mason KP, Green SM, Piacevoli Q, International Sedation Task F. Adverse event reporting tool to standardize the reporting and tracking of adverse events during procedural sedation: a consensus document from the world SIVA international sedation task force. Br J Anaesth. 2012;108(1):13-20.

14. Hans GA, Lauwick SM, Kaba A, Bonhomme V, Struys MM, Hans PC, et al. Intravenous lidocaine infusion reduces bispectral index-guided requirements of propofol only during surgical stimulation. Br J Anaesth. 2010;105(4):471-9.

15. Altermatt FR, Bugedo DA, Delfino AE, Solari S, Guerra I, Munoz HR, et al. Evaluation of the effect of intravenous lidocaine on propofol requirements during total intravenous anaesthesia as measured by bispectral index. Br J Anaesth. 2012;108(6):979-83.

16. Hegde SR, Iffrig K, Li T, Downey S, Heller SJ, Tokar JL, et al. Double-balloon enteroscopy in the elderly: safety, findings, and diagnostic and therapeutic success. Gastrointest Endosc. 2010;71(6):983-9.

17. Karan SB, Bailey PL. Update and review of moderate and deep sedation. Gastrointest Endosc Clin N Am. 2004;14(2):289-312.

18. van der Wal SE, van den Heuvel SA, Radema SA, van Berkum BF, Vaneker $M$, Steegers MA, et al. The in vitro mechanisms and in vivo efficacy of intravenous lidocaine on the neuroinflammatory response in acute and chronic pain. Eur J Pain. 2016;20(5):655-74.

19. Fassoulaki A, Melemeni A, Zotou M, Sarantopoulos C. Systemic ondansetron antagonizes the sensory block produced by intrathecal lidocaine. Anesth Analg. 2005;100(6):1817-21.

20. Hirota K, Okawa H, Appadu BL, Grandy DK, Lambert DG. Interaction of local anaesthetics with recombinant mu, kappa, and delta-opioid receptors expressed in Chinese hamster ovary cells. Br J Anaesth. 2000;85(5):740-6.

21. Woolf CJ, Wiesenfeld-Hallin Z. The systemic administration of local anaesthetics produces a selective depression of C-afferent fibre evoked activity in the spinal cord. Pain. 1985;23(4):361-74.
22. Liu J, Liu X, Peng LP, Ji R, Liu C, Li YQ. Efficacy and safety of intravenous lidocaine in propofol-based sedation for ERCP procedures: a prospective, randomized, double-blinded, controlled trial. Gastrointest Endosc. 2020;92(2):293-300.

23. Li X, Lv X, Jiang Z, Nie X, Wang X, Li T, et al. Application of intravenous Lidocaine in obese patients undergoing painless colonoscopy: a prospective, randomized, double-blind, controlled study. Drug Des Devel Ther. 2020;14:3509-18.

24. Chen M, Lu Y, Liu H, Fu Q, Li J, Wu J, et al. The propofol-sparing effect of intravenous lidocaine in elderly patients undergoing colonoscopy: a randomized, double-blinded, controlled study. BMC Anesthesiol. 2020;20(1):132.

25. Feldheiser A, Aziz O, Baldini G, Cox BP, Fearon KC, Feldman LS, et al. Enhanced recovery after surgery (ERAS) for gastrointestinal surgery, part 2: consensus statement for anaesthesia practice. Acta Anaesthesiol Scand. 2016;60(3):289-334.

\section{Publisher's Note}

Springer Nature remains neutral with regard to jurisdictional claims in published maps and institutional affiliations.

Ready to submit your research? Choose BMC and benefit from:

- fast, convenient online submission

- thorough peer review by experienced researchers in your field

- rapid publication on acceptance

- support for research data, including large and complex data types

- gold Open Access which fosters wider collaboration and increased citations

- maximum visibility for your research: over 100M website views per year

At BMC, research is always in progress.

Learn more biomedcentral.com/submissions 